\title{
Alagille Syndrome: Features and Outcome among Filipino Children
}

\author{
Germana Emerita V. Gregorio and Jossie M. Rogacion \\ Department of Pediatrics, College of Medicine and Philippine General Hospital, University of the Philippines Manila
}

\begin{abstract}
We report 13 children fulfilling criteria of Alagille syndrome. All had chronic cholestasis secondary to paucity of intrahepatic bile ducts and triangular facies. Eight children had associated congenital heart disease (six pulmonic stenosis, one each tetralogy of Fallot and patent ductus arteriosus), seven with butterfly vertebrae and one with posterior embryotoxon. Seven of the 13 children are alive and jaundice-free but three with concomitant hypercholesterolemia; the six other children died of liver-related complications.
\end{abstract}

Key Words: Butterfly vertebrae, infantile jaundice, facial malformation, paucity of intrahepatic bile ducts

\section{INTRODUCTION}

Alagille syndrome (AGS) is an autosomal dominant disorder characterized by the presence of at least three of five major criteria: 1) chronic cholestasis secondary to paucity of intrahepatic bile ducts (IHBD); 2) congenital heart disease; 3) facial dysmorphism; 4) butterfly vertebrae and 5) posterior embryotoxon. ${ }^{1-4}$ Two additional phenotypic criteria have been proposed - abnormalities of the kidneys and abnormalities of the vasculature - which are also important manifestations of AGS. Moreover, the presence of two major criteria with confirmed AGS in a first-degree relative may also be sufficient for a diagnosis. ${ }^{5}$

The disease is caused by a mutation in the Jagged-1 gene, which is important in cell differentiation and regulation during the development of the biliary epithelium. ${ }^{6-8}$ Once a diagnosis of AGS is made, the treatment and outcome are largely determined by the extent of the hepatic and cardiac disorders. ${ }^{9,10}$ The most common cardiovascular anomaly is the presence of peripheral pulmonic stenosis in 35 to $85 \%$ of AGS; in around $30 \%$ of cases, it maybe either atrial or ventricular septal defect, tetralogy of Fallot or pulmonary atresia. ${ }^{1,4,11,12}$ Progressive liver failure due to paucity of $\mathrm{IHBD}^{13}$ or growth impairment, refractory pruritus and debilitating xanthomas due to chronic cholestasis may occur. ${ }^{9,10}$ Development of hepatocellular carcinoma has also been reported in children with AGS, ${ }^{14}$ the youngest of whom was a 3 -year-old. ${ }^{15}$

AGS occurs in 1 in 100,000 live births but the incidence may be underestimated. ${ }^{15}$ It has never been reported among

Corresponding author: Germana Emerita V. Gregorio, MD, PhD Department of Pediatrics

Philippine General Hospital

University of the Philippines Manila

Taft Avenue, Manila 1000, Philippines

Email: gvgregorio@up.edu.ph

Filipino children. This study describes 13 patients diagnosed with AGS at the Section of Pediatric Gastroenterology, Hepatology and Nutrition of the Philippine General Hospital from 2000-2018. The clinical, biochemical, histological features and outcomes of these patients are discussed. 


\section{MATERIALS AND METHODS}

Based on the accepted criteria in the year 2000 at the time this study was initiated, AGS was diagnosed if at least three of the five major clinical features were present. ${ }^{1-4}$ Chronic cholestasis was defined as persistence of direct hyperbilirubinemia beyond 6 months of age. ${ }^{3}$ All patients underwent percutaneous liver biopsy and paucity of IHBD was reported as present if the ratio of the number of intralobular bile ducts to the number of portal tracts was less than 0.5..$^{16,17}$ The presence of congenital heart disease based on physical examination was confirmed by $2 \mathrm{D}$ echocardiogram. The presence of any vertebral anomalies was noted on radiologic evaluation of the vertebrae. Ophthalmologic examination, consisting of gonioscopy and slit lamp examination, was performed to assess presence of posterior embryotoxon. The cholesterol and triglyceride levels were considered increased if the values were beyond the upper limit for the age of the patient. Standard liver function tests, prothrombin time and international normalized ratio (INR) were done at baseline and on follow up as needed.

Parents were informed and agreed that the data of the patients will be included in this case series of patients with Alagille syndrome.

\section{RESULTS}

\section{Clinical features}

During the study period, 13 children (8 males) were diagnosed to have AGS (Table 1). All patients had a history of jaundice starting on the first month of life; the mean age of consult with a physician for the jaundice was 3 months (range, 2-9). Of the 13, 5 underwent initial liver biopsy at mean age of 2.5 months (range, 2 to 3.5 ) and was interpreted as giant cell hepatitis. However, one of the five patients had persistent acholic stools and eventually underwent a hepaticojejunostomy operation after an intraoperative cholangiogram that showed no passage of dye in the duodenum. In these five patients, paucity of IHBD (Figure 1) was only documented during the second liver biopsy that was done at a mean age of 23 months (range, 11 to 50) after the first one. For the remaining eight patients, paucity of IHBD was documented during the initial liver biopsy performed later at mean age of 18 months (range, 3 to 38 ). Other characteristic features that were noted in this case series included characteristic triangular facies in all patients, presence of congenital heart disease in eight, vertebral anomalies in nine and posterior embryotoxon in one patient. The vertebral anomalies consisted of butterfly vertebrae in seven, and spina bifida and scoliosis in one each. One patient also had clubfoot. Other anomalies identified

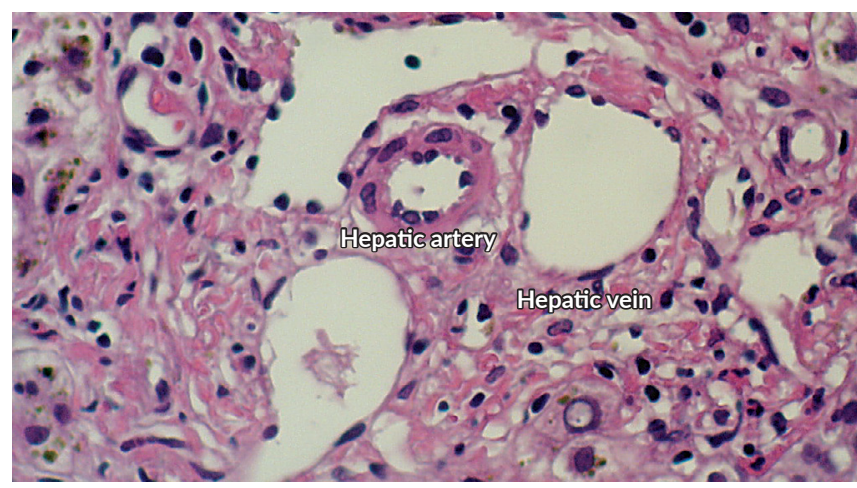

Figure 1. Liver biopsy of a patient (patient \#9) with Alagille Syndrome showing a portal tract with absence of bile duct and only the hepatic artery and veins are present.

Table 1. Clinical features of 13 patients diagnosed with Alagille's Syndrome

\begin{tabular}{|c|c|c|c|c|c|c|c|c|}
\hline $\begin{array}{l}\text { Case } \\
\text { No. }\end{array}$ & Sex & $\begin{array}{c}\text { Age at Initial } \\
\text { Consult } \\
\text { (months) }\end{array}$ & $\begin{array}{c}\text { Age at } \\
\text { Diagnosis } \\
\text { (months) }\end{array}$ & $\begin{array}{l}\text { Facial } \\
\text { Feature }\end{array}$ & Congenital heart disease & $\begin{array}{c}\text { Skeletal } \\
\text { Abnormality }\end{array}$ & $\begin{array}{c}\text { Posterior } \\
\text { Embryotoxon }\end{array}$ & $\begin{array}{l}\text { Other } \\
\text { anomalies }\end{array}$ \\
\hline 1 & M & 2.0 & 19.3 & Present & None & Butterfly vertebrae & Absent & Regal agenesis \\
\hline 2 & M & 2.2 & 17.8 & Present & Pulmonic Stenosis & Clubfoot & Present & \\
\hline 3 & M & 1.6 & 28.2 & Present & Patent Ductus Arteriosus & None & Absent & \\
\hline 4 & M & 3.1 & 50.3 & Present & Bilateral Pulmonic Stenosis & Spina Bifida & Absent & \\
\hline 5 & $\mathrm{~F}$ & 3.5 & 11.9 & Present & Pulmonic Stenosis & Butterfly vertebrae & Absent & \\
\hline 6 & M & 10.3 & 10.5 & Present & $\begin{array}{l}\text { Pulmonic Stenosis, valvar with } \\
\text { pulmonary valve annulus of } 0.8 \mathrm{~cm}\end{array}$ & Butterfly vertebrae & Absent & \\
\hline 7 & M & 3.0 & 8.1 & Present & None & Butterfly vertebrae & Absent & \\
\hline 8 & M & 3.1 & 30.1 & Present & $\begin{array}{l}\text { Tetralogy of Fallot with moderate valvar } \\
\text { to supravalvular pulmonic stenosis }\end{array}$ & Butterfly vertebrae & Absent & \\
\hline 9 & $\mathrm{~F}$ & 3.1 & 38.4 & Present & None & Butterfly vertebrae & Absent & \\
\hline 10 & M & 3.4 & 24.6 & Present & None & Scoliosis & Absent & $\begin{array}{l}\text { Gall bladder } \\
\text { polyps }\end{array}$ \\
\hline 11 & $\mathrm{~F}$ & 2.1 & 7.1 & Present & Pulmonic Stenosis, supravalvular & None & Absent & \\
\hline 12 & $\mathrm{~F}$ & 2.8 & 2.8 & Present & Pulmonic Artery Stenosis, left and right & Butterfly vertebrae & Absent & \\
\hline 13 & $\mathrm{~F}$ & 28.6 & 28.6 & Present & None & Butterfly vertebrae & Absent & \\
\hline
\end{tabular}


Table 2. Laboratory features of 13 patients at the time of diagnosis of Alagille's Syndrome, mean \pm SD

\begin{tabular}{lrr} 
& Mean & \multicolumn{1}{c}{ SD } \\
\hline Total bilirubin, $\mu \mathrm{mol} / \mathrm{L}$ (nv: $\leq 20)$ & 265.1 & 211.0 \\
Direct bilirubin, $\mu \mathrm{mol} / \mathrm{L}$ (nv: $\leq 20)$ & 188.3 & 111.2 \\
Alanine transaminase, IU/L (nv: $\leq 50)$ & 246.8 & 164.7 \\
Aspartate aminotransferase, IU/L (nv: $\leq 50)$ & 293.1 & 147.7 \\
Gamma glutamyl transpeptidase, IU/L (nv: $\leq 50),(\mathrm{n}=9)$ & 758.4 & 778.1 \\
Alkaline phosphatase, IU/L (nv: $\leq 350)$ & 673.1 & 442.0 \\
Albumin, g/L (nv: 35-50) & 31.8 & 6.2 \\
International normalized prothrombin ratio & 1.1 & 0.04 \\
(nv: 1.0-1.2) & & \\
Cholesterol, mmol/L (nv: <4.2) (n=11) & 6.8 & 3.6 \\
Triglycerides, mmol/L (nv: <1.0) (n=11) & 2.7 & 1.2 \\
\hline
\end{tabular}

were renal agenesis and gall bladder polyps; the latter was eventually excised when the patient developed acute cholecystitis at 5 years of age.

\section{Biochemical features}

Baseline biochemical examinations showed that all patients had markedly elevated bilirubin and enzyme levels (Table 2). All had normal international normalized ratio. The serum albumin values were less than $30 \mathrm{~g} / \mathrm{L}$ in three cases. On follow-up in 11 patients, there were elevated cholesterol levels in 9 patients (Mean $6.8 \mathrm{mmol} / \mathrm{L}$ [SD 3.6];
$\mathrm{NV}<5.2$ ), and elevated triglyceride levels in 10 patients (Mean $2.7 \mathrm{mmol} / \mathrm{L}$ [SD 1.2]; NV < 1.0).

\section{Outcome}

Of the 13 patients, seven are alive and six died. Those who are alive were followed up for a mean duration of 5.8 years (range, 2-15) after diagnosis. In all seven living patients, the jaundice disappeared and their development was at par with age. Weight was appropriate for height although there was linear growth retardation (Weight for height $\mathrm{Z}$ score < -3). Three of the seven had hypercholesterolemia, with values of $5.5,7.2$ and $9.37 \mathrm{mmol} / \mathrm{L}$; the latter two opted for treatment with cholestyramine. All three developed debilitating xanthomas (Figure 2).

The six patients who died were followed up for mean duration of 6.4 years (range, 3 to 11) from the time of diagnosis. All had persistent jaundice, poor weight gain and linear growth, severe pruritus, xanthomas and signs of decompensated liver disease, including presence of ascites and deranged prothrombin time unresponsive to vitamin $\mathrm{K}$ administration. All were advised liver transplantation for long-term survival. The cause of death was liver failure before transplant could be done in 3 patients including a boy who was initially diagnosed with extrahepatic biliary atresia and underwent a hepaticojejunostomy operation. One 5-year-old patient had sudden death with no autopsy performed. Two patients died post-liver transplant surgery;
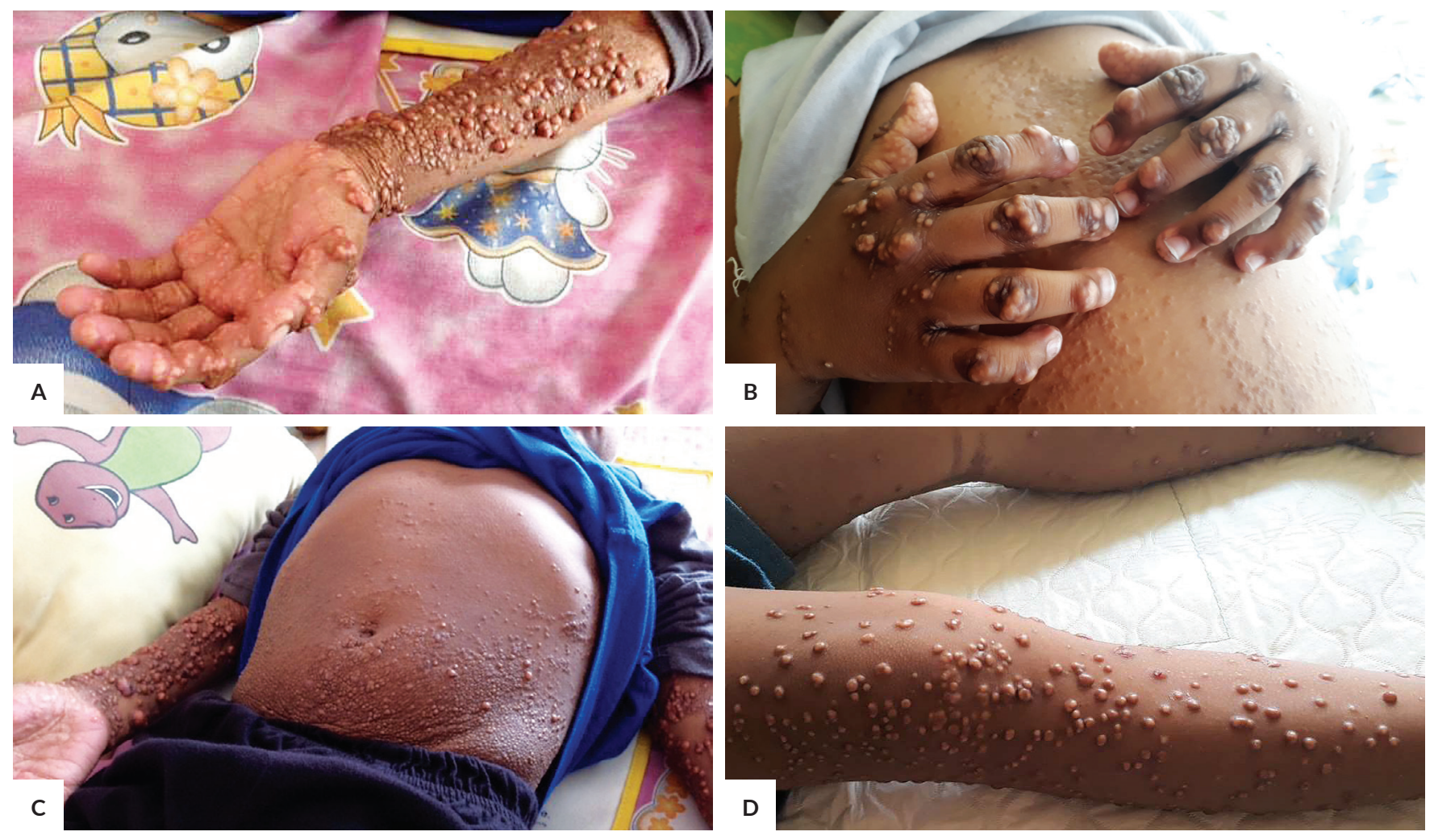

Figure 2. Debilitating xanthomas of patients with Alagille Syndrome and hypercholesterolemia in the (A) arms, (B) hands, (C) abdomen and (D) legs. 
one from unexpected intracranial bleeding at six weeks and the other from acute respiratory distress syndrome within a week after the surgery.

\section{DISCUSSION}

Over an 18-year period, we have diagnosed 13 Filipino children with Alagille syndrome based on clinical and liver histological features. Worldwide, the incidence of the disease is 1: 40,000 to 1: 100,000 and comprised $7 \%$ of all neonatal cholestasis cases in a specialized liver center in the United Kingdom. ${ }^{2}$ In a local 5-year survey from 2006-10, 9 of $376(2.4 \%)$ cases presenting with jaundice in infancy were diagnosed as Alagille syndrome. ${ }^{17}$ Among Asians, Alagille syndrome has only been reported as case reports from India, ${ }^{18-20} \mathrm{China}^{21}$ and in genetic studies among Vietnamese cohorts. ${ }^{22}$ It has never been reported among Filipino children.

All our patients paucity of IHBD was documented histologically defined as a ratio of bile ducts to portal tracts of less than 0.5 in a specimen with at least six portal tracts. In five patients, a repeat liver biopsy was needed to make a diagnosis of paucity of IHBD since the initial one only showed non-specific giant cell hepatitis. This data is in conformity with studies showing that $25 \%$ of liver biopsies taken even after one year of age may still not show paucity of IHBD.,23 Currently, liver biopsy is no longer considered mandatory to make a diagnosis. ${ }^{5}$ In the absence of the characteristic histological feature, a patient may still be classified as Alagille syndrome in the presence of cholestasis and two other classic criteria: ${ }^{5}$ either facial dysmorphism, congenital heart disease, skeletal and ophthalmologic abnormalities, and renal and vascular defects.

The characteristic facial features of Alagille syndrome consist of a broad forehead and deep-set eyes with pointed chin giving the face a triangular shape. Although 70 to $98 \%$ of patients diagnosed with Alagille syndrome have the characteristic facial feature, this may not be present at onset and may develop only over time. ${ }^{1-4,10,11}$ In all our patients, the diagnosis based on the presence of the facial feature was not suspected before referral to our institution. Another clue to the diagnosis of Alagille syndrome is the presence of a cardiac murmur on auscultation in a jaundiced infant. Eight patients in this series had concomitant congenital heart disease, the majority of which were peripheral pulmonic stenosis. In larger cohorts of patients with Alagille syndrome, the prevalence of cardiac murmur is higher at 85 to $98 \% .^{1-4,10,11}$ Other features of this syndrome include vertebral anomalies that are documented in 33 to $85 \%$ and posterior embryotoxon in 56 to $88 \%$ of cases. In our series, nine of our 13 patients had vertebral anomaly, in keeping with the reported prevalence worldwide, but only one had posterior embryotoxon, a prominent Schwalbe ring at the junction of the cornea and iris. Whether the absence of posterior embryotoxon in the anterior chamber was only missed out on routine ophthalmologic examination or this is a phenotypic variation of Alagille syndrome in our race remains to be known. It has been suggested that abnormal accumulation of protein and calcium salts in the optic nerve (optic nerve drusen) was more common than the presence of posterior embryotoxon (91\% vs 69\%) among 32 patients with AGS. ${ }^{24}$

Since infants with Alagille syndrome will present as neonatal cholestasis, i.e., persistent jaundice beyond two weeks of life, a hepatobiliary ultrasound ${ }^{25}$ is important to exclude other liver pathologies such as biliary atresia. Ultrasound findings favoring the diagnosis of Alagille syndrome over biliary atresia include the absence of triangular cord sign, hepatic artery enlargement and signs of portal hypertension, such as splenomegaly and ascites. A small gallbladder appeared in both Alagille syndrome (86\%) and biliary atresia $(81 \%)$ on ultrasound. Similarly, non-visualization of the extrahepatic biliary tree on magnetic resonance cholangiopancreatography did not differ significantly between the two conditions (75\%, Alagille vs $93 \%$, biliary atresia). Another imaging study, such as hepatobiliary iminodiacetic acid scan, is also not specific for Alagille syndrome since the absence of passage of dye from the bile ducts to the duodenum may lead to a diagnosis of biliary atresia. ${ }^{26}$

The outcome for liver disease among patients diagnosed with Alagille syndrome may be extremely variable. In a longitudinal study of laboratory parameters among patients with Alagille syndrome, a direct bilirubin greater than 77 $\mu \mathrm{mol} / \mathrm{L}$ and cholesterol greater than $13.5 \mu \mathrm{mol} / \mathrm{L}$ below 5 years of age was shown to be associated with a more severe liver disease in later life. ${ }^{27}$ The presence of cholestasis in infancy in the seven patients who are alive, which was controlled with medical treatment, is consistent with this observation. In contrast, the six patients who have died had unremitting cholestasis that included persistent jaundice, severe pruritus, xanthelasma and evidence of synthetic dysfunction of liver.

Liver transplantation in Alagille syndrome is a therapeutic option with a reported 1-year survival between 80 to $85 \% .{ }^{28,29}$ However, one must carefully screen for suitable transplant candidates. The operation may resolve cholestasis and improve quality of life but the concomitant renal disease may worsen with intake of nephrotoxic immuno-suppressant drugs. Majority of studies showed that linear growth does not improve even after successful operation. ${ }^{28,30}$ Two of our patients who underwent liver transplant died: one, from unexplained intracranial bleeding and the other from acute respiratory distress syndrome. In a study of Alagille syndrome, ${ }^{31} 25$ of 268 (9\%) patients were noted to have vascular complications but only 16 had documented vessel abnormalities. In the nine remaining patients (8 children) without structural lesions, two were children who developed intracranial bleeding postliver transplant. Other cerebral abnormalities present in Alagille syndrome include Moyamoya arteriopathy, cerebral aneurysm and dolichoectasia. ${ }^{32}$ On the other hand, $16 \%$ $(17 / 104)$ of patients who underwent liver transplant for end-stage liver disease developed acute respiratory distress syndrome between one to four days after transplant. ${ }^{33}$ 
In summary, Alagille syndrome should be included in the differential diagnosis of any child with chronic cholestasis, especially in the presence of the characteristic facies and a cardiac murmur on auscultation. Liver transplantation is a therapeutic option for patients with unremitting cholestasis and intractable pruritus but needs careful evaluation due to the multisystem nature of this condition.

\section{Statement of Authorship}

Both authors participated in data collection and analysis, and approved the final version submitted.

\section{Author Disclosure}

Both authors declared no conflicts of interest.

\section{Funding Source}

None.

\section{REFERENCES}

1. Alagille D, Estrada A, Hadchouel M, Gautier M, Odièvre M, J P Dommergues JP. Syndromic paucity of interlobular bile ducts (Alagille syndrome or arteriohepatic dysplasia): review of 80 cases. J Pediatr. 1987 Feb; 110(2):195-200.

2. Subramaniam P, Knisely A, Portmann B, Qureshi SA, Aclimandos WA, Karani JB, et al. Diagnosis of Alagille's syndrome -25 years of experience at King's College Hospital. J Pediatr Gastroenterol Nutr. 2011 Jan; 52(1):84-9.

3. Emerick KM, Rand EB, Goldmuntz E, Krantz ID, Spinner NB, Piccoli DA. Features of Alagille syndrome in 92 patients: frequency and relation to prognosis. Hepatology. 1999 Mar; 29(3):822-9.

4. Quiros-Tejeira RE, Ament ME, Heyman MB, Martin MG, Rosenthal P, Hall TR, et al. Variable morbidity in Alagille syndrome: a review of 43 cases. J Pediatr Gastroenterol Nutr. 1999 Oct; 29(4):431-7.

5. Saleh M, Kamath BM, Chitayat D. Alagille syndrome: clinical perspectives. App Clin Genet. 2016 Jun; 9:75-82.

6. Oda T, Elkahloun AG, Pike BL, K Okajima, I D Krantz, A Genin, et al. Mutations in the human Jagged I gene are responsible for Alagille syndrome. Nat Genet. 1997 Jul; 16(3):235-42.

7. Li L, Krantz ID, Deng Y, A Genin A, Banta AB, Collins CC, et al. Alagille syndrome is caused by mutations in human Jagged I, which encodes a ligand for Notch 1. Nat Genet. 1997 Jul; 16(3):243-51.

8. Crosnier C, Attie-Bitach T, Encha-Razavi F, Audollent S, Soudy F, Hadchouel M, et al. JAGGED 1 gene expression during human embryogenesis elucidates the wide phenotypic spectrum of Alagille syndrome. Hepatology. 2000 Sep; 32(3):574-81.

9. Lykavieris P, Hadchouel M, Chardot C, Bernard O. Outcome of liver disease in children with Alagille syndrome: a study of 163 patients. Gut. 2001 Sep; 49(3):431-5.

10. Hoffenberg EJ, Narkewicz MR, Sonheimer JM, Smith DJ, Silverman A, Sokol RJ. Outcome of syndromic paucity of interlobular bile ducts (Alagille syndrome) with onset of cholestasis in infancy. J Pediatr. 1995 Aug; 127(2):220-4.

11. Deprettere A, Portman B, Mowat AP. Syndromic paucity of the intrahepatic bile ducts: diagnostic difficulty; Severe morbidity throughout early childhood. J Pediatr Gastroenterol Nutr. 1987 Nov-Dec; 6(6):865-71.

12. Krantz ID, Piccoli DA, Spinner NB. Alagille syndrome. J Med Genet. $1997 \mathrm{Feb} ; 34(2): 152-7$.

13. Frongillo F, Bianco G, Silvestrini N, Lirosi MC, Sanchez AM, Nure E, et al. Acute liver failure in an adult, a rare complication of Alagille syndrome: case report and brief review. Transplant Proc. 2015 Sep; 47(7):2179-81.
14. Bhadri VA, Stormon MO, Arbuckle S, Lam AH, Gaskin KJ, Shun A. Hepatocellular carcinoma in children with Alagille Syndrome. J Pediatr Gastroenterol Nutr. 2005 Nov; 41(5):676-8.

15. Wetli SC, Gralla ES, Schibli S, Strazinger E. Hepatocellular carcinoma and regenerating nodule in a 3-year-old child with Alagille syndrome. Pediatr Radiol. 2010 Oct; 40(10):1696-8.

16. Koçak N, Gürakan F, Yüce A, Cağlar M, Kale G, Göğüş S. Nonsyndromic paucity of interlobular bile ducts: Clinical and laboratory findings of 10 cases. J Pediatr Gastroenterol Nutr. 1997 Jan; 24(1):44-8.

17. Vitug JD, Avila JMC, Gregorio GV. Histological pattern and outcome of Filipino children with liver disease who underwent percutaneous liver biopsy: a five-year survey. Acta Med Philipp. 2015 Oct-Dec; 49(4):12-7.

18. Srivastava A, Goel D, Bolia R, Poddar U, Yachha SK. Alagille syndrome: experience of a tertiary care center in North India. Indian J Gastroenterol. 2014 Jan; 33(1):59-62.

19. Sengupta S, Das JK, Gangopadhyay A. Alagille syndrome with prominent skin manifestations. Indian J Dermatol Venereol Leprol. 2005 Mar-Apr; 71(2):119-21.

20. Bhatia V, Kumar P. Alagille syndrome with a previously undescribed mutation. Indian Pediatr. 2014 Apr; 51(4):314-6.

21. Liu Y, Wang H, Dong C, Feng JX, Huang ZH. Clinical features and genetic analysis of pediatric patients with Alagille syndrome presenting initially with liver function abnormalities. Curr Med Sci. 2018 Apr; 38(2):304-9.

22. Lin HC, Hoang PL, Hutchinson A, Chao G, Gerfen J, Loomes $\mathrm{KM}$, et al. Alagille syndrome in a Vietnamese cohort: Mutation analysis and assessment of facial features. Am J Med Genet A. 2012 May; 158A(5):1005-13.

23. Hashida Y, Yunis EJ. Syndromic paucity of interlobular bile ducts: hepatic histopathology of the early and end-stage liver. Pediatr Pathol. 1988; 8(1):1-15.

24. El-Koofy NM, El-Mahdy R, Fahmy ME, El-Hennawy A, Farag MY, El-Karaksy HM. Alagille syndrome: clinical and ocular pathognomonic features. Eur J Ophthalmol. 2011 Mar-Apr; 21(2): 199-206.

25. Han S, Jeon TY, Hwang SM, Yoo SY, Choe YH, Lee SK, et al. Imaging findings of Alagille syndrome in young infants: differentiation from biliary atresia. Br J Radiol. 2017 Aug; 90(1077):20170406

26. Donia AE, Ibrahim SM, Kader MS, Saleh AM, E1-Hakim MS, El-Shorbagy MS, et al. Predictive value of assessment of different modalities in the diagnosis of infantile cholestasis. J Int Med Res. 2010; 38(6):2100-16.

27. Kamath BM, Munoz PS, Bab N, Baker A, Chen Z, Spinner NB, et al. A longitudinal study to identify laboratory predictors of liver disease outcome in Alagille syndrome. J Pediatr Gastroenterol Nutr. 2010 May; 50(5):526-30.

28. Kamath BM, Yin W, Miller H, Anand R, Rand EB, Alonso E, et al. Outcomes of liver transplantation for patients with Alagille syndrome: the studies of pediatric liver transplantation experience. Liver Transpl. 2012 Aug; 18(8):940-8.

29. Lee CN, Tiao MM, Chen HJ, Concejero A, Chen CL, Huang YH. Characteristics and outcome of liver transplantation in children with Alagille syndrome: a single-center experience. Pediatr Neonatol. 2014 Apr; 55(2):135-8.

30. Pawlowska J, Socha P, Jankowska I. Factors affecting catch-up growth after liver transplantation in children with cholestatic liver diseases. Ann Transplant. 2010 Jan-Mar; 15(1):72-6.

31. Kamath BM, Spinner NB, Emerick KM, Chudley AE, Booth C, Piccoli DA, et al. Vascular anomalies in Alagille syndrome: A significant cause of morbidity and mortality. Circulation. 2004 Mar; 109(11):1354- 8

32. Carpenter CD, Linscott LL, Leach JL, Vadivelu S, Abruzzo T. Spectrum of cerebral arterial and venous abnormalities in Alagille syndrome. Pediatr Radiol. 2018 Apr; 48(4):602-8.

33. Li GS, Ye QF, Xia SS, Chen ZS, Zeng FJ, Lin ZB, et al. Acute respiratory distress syndrome after liver transplantation: Etiology, prevention and management. Hepatobiliary Pancreat Dis Int. 2002 Aug; 1(3):330-4. 